\title{
Reflectance Spectra of "Featureless"' Materials and the Surface Mineralogies of M- and E-Class Asteroids
}

\author{
Edward A. Cloutis \\ Department of Geology, University of Alberta, Edmonton, Canada \\ Michael J. Gaffey \\ Department of Geology, Rensselaer Polytechnic Institute, Troy, New York \\ Dorian G. W. Smith and Richard St. J. Lambert \\ Department of Geology, University of Alberta, Edmonton, Canada
}

\begin{abstract}
The 0.3- to 2.6- $\mu \mathrm{m}$ reflectance spectra of meteoritic enstatite (nearly pure $\mathrm{MgSiO}_{3}$ ), iron meteorite metal, magnetite and amorphous carbon, and various mixtures of these materials with mafic silicates have been measured in order to search for diagnostic spectral parameters which can be used to differentiate among the different materials and to provide information on the detection limits for mafic silicates. Enstatite and metal can be discriminated on the basis of albedo and spectral slopes. Metal, magnetite, and amorphous carbon are variably effective at suppressing mafic silicate absorption bands. Metal-silicate spectra suggest that $>\mathbf{2 5} \mathrm{wt} \%$ olivine must be present to be spectrally resolvable, while the lower limit for orthopyroxene is $\sim 10 \mathrm{wt} \%$. Magnetite-silicate spectra indicate that magnetite is not an effective suppressor of mafic silicate absorption bands and that fine-grained magnetite imparts a less red overall slope to mafic silicate spectra than coarse-grained magnetite. Carbon-silicate spectra indicate that suppression of olivine absorption bands is enhanced when the olivine is finely comminuted and is less effective at larger grain sizes. Carbon and magnetite both seem to be required to impart a blue overall slope to mafic silicate spectra and to suppress $\mathrm{Fe}^{2+}$ absorption bands. The small amount of carbon present in ordinary chondrites is probably not the cause of the flat reflectance spectra of metal-rich ordinary chondrite separates. The observational data for a representative M-class asteroid, (16) Psyche, are largely consistent with a fine-grained metal-rich surface assemblage, although an enstatite chondrite-like assemblage cannot be ruled out. The observational data for the Eclass asteroid (44) Nysa indicate that its surface is composed of fine-grained material similar to enstatite achondrites (aubrites), with a small amount of material comparable to the chondritic inclusions found in the Cumberland Falls aubrite.
\end{abstract}

\section{Introduction}

Telescopic spectral studies of asteroids provide the best available means for determining the surface compositions of these objects. There have been a number of notable successes in this area [e.g., McCord et al., 1970; Bell et al., 1984; Cruikshank and Hartmann, 1984; Gaffey, 1984]. A significant proportion of the main belt asteroids lack diagnostic features in the 0.3to $1.1-\mu \mathrm{m}$ wavelength region [Gaffey, 1978; Gaffey and McCord, 1978]. The $0.3-$ to $2.6-\mu \mathrm{m}$ bidirectional reflectance spectra of a number of "featureless" materials have been measured in order to search for diagnostic spectral parameters such as changes in spectral slope and presence or absence of absorption bands which can be used to overcome this difficulty. The samples include a number of ron-nickel alloys (both artificial and natural), meteoritic enstatite, amorphous carbon, iron oxides, and various mixtures of these phases with various mafic silicates. The reflectance spectra of meteoritic metal+mafic silicates, magnetite+mafic silicates, and amorphous carbon +mafic silicates are useful for determining the spectral detection limits for mafic silicates mixed with opaques.

That different meteorites possess unique spectral properties over even limited wavelength ranges has been known for some time [Watson, 1938]. As the wavelength range examined has increased, improved discrimination of different materials has resulted [Gaffey, 1976; Bell et al., 1988]. Most of the materials

\section{Copyright 1990 by the American Geophysical Union.}

Paper number 89JB01625.

$0148-0227 / 90 / 89 \mathrm{JB}-01625 \$ 05.00$ covered in this study have generally been ascribed to the featureless, and hence indistinguishable, class. For the sake of convenience they have been grouped into metals, silicates, carbon, and $\mathrm{Fe}$ oxides. These materials are a chemically heterogeneous group, and positive identification of any one of them, either singly or in conjunction with other minerals, would have important implications for understanding the evolution of a particular body.

The controversy over one group of asteroids, the M-class, involves a debate over whether they are differentiated metaldominated bodies [e.g. Dollfus et al., 1979; Britt and Pieters, 1988] or primitive objects similar to enstatite chondrites [Chapman and Salisbury, 1973; Chapman, 1976]. These asteroids are largely concentrated in the inner part of the main asteroid belt [Gradie and Tedesco, 1982]. If they are metal-rich bodies, then the case for pervasive and intense early heating of this region is strengthened [Bell, 1986]. If the $M$ asteroids are similar to the primitive enstatite chondrites, explanations must be devised to explain why these asteroids escaped the early heating event which seems to have affected other inner main belt groups such as the $\mathbf{S}$ and A classes (E.A. Cloutis et al., Metal-silicate mixtures: Spectral properties and applications to asteroid taxonomy, submitted to Journal of Geophysical Research, 1989). Resolution of such a basic issue has important implications for understanding the origin and early history of the asteroid belt and perhaps the solar system [Chapman, 1979; Bell, 1986; Gaffey, 1986, 1988].

\section{Experimental Data}

A number of natural and synthetic materials have been spectrally characterized. The metals are synthetic Fe powder

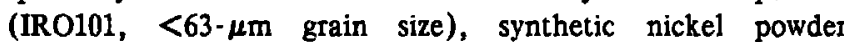


(NIC101, <37- $\mu \mathrm{m}$ grain size), synthetic pre-alloyed 50:50 iron:nickel powder (NIF101, <63- $\mu \mathrm{m}$ grain size), and a number of different size fractions of the Odessa, Texas, coarse octahedrite (MET101), which is predominantly composed of kamacite. The carbon is a synthetic amorphous carbon (LCA101, $<0.023-\mu \mathrm{m}$ grain size). The iron oxide group is represented by natural magnetite from the Jacupiranga Mine, Sao Paulo State, Brazil (MAG101), in various size fractions. The lone spectrally featureless silicate is a metal-f ree sample of the Happy Canyon E7 enstatite chondrite (PYX205). Carbon and magnetite have been incorporated into various mixtures with orthopyroxenes and olivine. The orthopyroxenes are from an unspecified locality in India (PYX117), and Ekersund, Norway (PYX032), and the olivine is from San Carlos, Arizona (OLV003).

The compositions of OLV003, PYX117, MET101, and MAG101 have been obtained by electron microprobe analysis at the University of Calgary SEMQ facility and are averages of 6-8 point analyses and area scans (Table 1 ). The data were reduced using Bence-Albee $\alpha$ and $\beta$ corrections. The $\mathrm{Fe}^{2+}$ values were obtained by wet chemical methods, and $\mathrm{Fe}^{3+}$ was obtained as the difference between total and ferrous uron. For the iron meteorite, only the kamacite, which forms the bulk of the sample [Buchwald, 1975] was analyzed (MET101). The composition of the pyroxene in Happy Canyon is given by Watters and Prinz [1979].

The Happy Canyon E7 sample was prepared by crushing the sample in an alumina mortar and pestle and was acid treated to remove the pervasive iron oxide contaminants and metal. The magnetite and silicate samples were obtained by crushing in the same manner. The required phases were separated through a combination of magnetic separation and hand picking. The cleaned samples were repeatedly wet sieved with acetone to obtain well-sorted size ranges. The meteoritic metal was ob-

Table 1. Chemical Composition of the Minerals Used in This Study.

\begin{tabular}{|c|c|c|c|c|c|}
\hline & OLV003 & PYX117 & MAG101 & & MET101 \\
\hline $\mathrm{SiO}_{2}$ & 40.64 & 53.54 & N.D. & $\mathrm{Si}$ & N.D \\
\hline $\mathrm{FeO}$ & 9.25 & 16.17 & 26.52 & $\mathrm{Fe}$ & 93.39 \\
\hline $\mathrm{Fe}_{2} \mathrm{O}_{3}$ & 0.59 & 1.02 & 63.71 & $\cdots$ & \\
\hline $\mathrm{MgO}$ & 49.13 & 27.53 & 3.63 & $\mathrm{Mg}$ & 0.00 \\
\hline $\mathrm{CaO}$ & 0.07 & 0.35 & N.D. & $\mathrm{Ca}$ & N.D. \\
\hline $\mathrm{Al}_{2} \mathrm{O}_{3}$ & $<0.01$ & 1.54 & 0.33 & $\mathrm{~A} 1$ & 0.03 \\
\hline $\mathrm{NiO}$ & 0.33 & 0.05 & N.D. & $\mathrm{Ni}$ & 6.07 \\
\hline $\mathrm{TiO}_{2}$ & 0.00 & 0.03 & 3.04 & $\mathrm{~T}_{1}$ & 0.00 \\
\hline $\mathrm{MnO}$ & 0.09 & 0.44 & 0.60 & $\mathrm{Mn}$ & 0.00 \\
\hline $\mathrm{Cr}_{2} \mathrm{O}_{3}$ & 0.01 & 0.07 & 0.03 & $\mathrm{Cr}$ & 0.1 \\
\hline $\mathrm{Na}_{2} \mathrm{O}$ & 0.00 & 0.00 & N.D. & $\mathrm{Na}$ & 0.00 \\
\hline $\mathrm{ZnO}$ & 0.00 & N.D. & N.D. & $\mathrm{Zn}$ & 0.11 \\
\hline $\mathrm{CoO}$ & 0.04 & 0.01 & N.D. & Co & 0.50 \\
\hline $\mathrm{V}_{2} \mathrm{O}_{5}$ & 0.00 & 0.00 & N.D. & $\mathrm{V}$ & 0.00 \\
\hline $\mathrm{K}_{2} \mathrm{O}$ & 0.00 & N.D. & N.D. & $\mathbf{K}$ & N.D. \\
\hline \multirow[t]{5}{*}{$\mathrm{ZrO}_{2}$} & N.D. & 0.00 & N.D. & $\mathrm{Zr}_{\mathbf{r}}$ & N.D. \\
\hline & & & & $S$ & 0.00 \\
\hline & & & & $\mathbf{P}$ & 0.02 \\
\hline & & & & $\mathrm{Cu}$ & 0.00 \\
\hline & & & & $\mathrm{Pb}$ & 0.87 \\
\hline Total & 100.15 & 100.75 & 97.87 & & 101.17 \\
\hline
\end{tabular}

Values in weight percent.

0.00 tained by grinding an unweathered, interior sample of the meteorite with an emery grinder and magnetically separating the grinding wheel contaminants. A portion of this powder was beaten in the alumina mortar and pestle in order to obtain a more equidimensional grain shape and was wet sieved with acetone. The 45- to $90-\mu \mathrm{m}$ beaten portion of the powder will be referred to as MET101b to distinguish it from the unbeaten 45- to $90-\mu \mathrm{m}$ sample. The $\langle 45-\mu \mathrm{m}$ and $125-$ to $355-\mu \mathrm{m}$ fractions are the unbeaten samples. Immediately following the sieving, the meteoritic metal powders were transferred to a dry nitrogen environment, separated into splits for $X$ ray diffraction and spectral analysis, and sealed. The artificial metal powders were opened in the nitrogen environment, split, and resealed. The various mineral mixtures have been prepared on a weight percentage basis (e.g., a mixture of $75 \mathrm{wt} \%$ metal and $25 \mathrm{wt} \%$ pyroxene is referred to as $75 / 25 \mathrm{MET} / \mathrm{PYX}$ ).

The reflectance spectra were acquired at the RELAB spectrometer facility at Brown University and at the U.S. Geological Survey facility in Denver, Colorado. Details of the instrumentation are given by Pieters [1983] and King and Ridley [1987], respectively. The spectra measured at the RELAB facility were acquired at $0^{\circ}$ incidence and $15^{\circ}$ emission and a spectral resolution of $5 \mathrm{~nm}$. All but the three size fractions of MET101 (unbeaten) were measured at the RELAB facility. The spectra measured at the U.S. Geological Survey were acquired using an integrating sphere arrangement. All the spectra were measured relative to halon, a near-perfect diffuse reflector in the $0.3-$ to $2.7-\mu \mathrm{m}$ region [Weidner and Hsia, 1981], and corrected for minor ( $2 \%)$ irregularities in halon's absolute reflectance in the $2-\mu \mathrm{m}$ region, as well as for dark current offsets. The reflectance spectra were processed using the Gaffey Spectrum Processing System, a PC compatible version of SPECPR [Clark, 1980].

\section{Results}

The various reflectance spectra have been subdivided on the same basis used earlier, metals, silicates, carbon, and iron oxides, since the presence of each group has important genetic implications for remote sensing analysis. The pure metal and metal-silicate spectra provide information on the detection limits for silicates in these types of assemblages. Carbon-silicate and magnetite-silicate mixtures have been examined for silicate detection himits and for the presence of diagnostic spectral features in the opaque phases.

\section{Metal}

Metallic nickel-iron is the dominant component in iron meteorites [Buchwald, 1975], and can comprise a substantial 0.00 portion of many other meteorite classes [e.g., Mason, 1962].

0.00 The spectral properties of meteoritic metal and the detection

0.18 limits for silicates in metal-silicate mixtures are important for

0.00 determining whether the parent bodies of various metal-rich 0.11 meteorites can be identified.

0.50 The vast majority of iron meteorites and nickel-iron alloys 0.00 show a gradual increase in reflectance from $0.2-$ to $2.7-\mu \mathrm{m}$.

N.D. The only exception seems to be flat plates with a surface N.D. roughness less than the wavelength of light [Britt and Pieters, 0.00 1988]. Other flat, polished alloys and iron meteorites show the 0.02 expected red slope (reflectance increasing toward longer 0.00 wavelengths) [Yolken and Kruger, 1965; Blodgett and Spicer,

0.87 1967; Gorban et al., 1973; Gorban and Stashchuk, 1974;

101.17 Miyamoto, 1987]. All powdered specimens show a red slope [Johnson and Fanale, 1973; Gaffey, 1974; Dollfus et al., 1980; Britt and Pieters, 1988]. This applies to even very fine-grained 
specimens with particle diameters of a few tens of microns or less [Felerberg et al., 1982; McFadden, 1983; Gaffey, 1986; Wagner et al., 1987] and meta]-coated particles [Bell and Mao, 1977].

The reflectance properties of metal are a function of the composition and grain size/surface roughness of the sample. In order to understand the relative importance of these parameters, the reflectance spectra of a series of well-characterized meteorite and artificial metals have been measured. The compositional dependence of the spectra has been investigated using metal powders with roughly equivalent grain sizes, IRO101 $(<63 \mu \mathrm{m})$, NIC101 $(<37 \mu \mathrm{m})$, NIF101 $(<63 \mu \mathrm{m})$, and the MET101 samples. The effect of grain size on spectral reflectance has been determined from the four size fractions of the Odessa iron meteorite, $<45 \mu \mathrm{m}, 45-90 \mu \mathrm{m}, 45-90 \mu \mathrm{m}$ beaten, and 125-355 $\mu \mathrm{m}$. A mixture of 99.5:0.5 meteoritic metal:amorphous carbon has been spectrally characterized in order to investigate the effect of opaque phases on metal spectra. The absolute and normalized reflectance spectra of some of the metals are shown in Figures 1 and 2. All show a red slope with no well-defined absorption bands. The slopes of the nonmeteoritic metals (Figure 1) show differences in spectral slope presumably due to composition since the grain sizes are all comparable. The reflectance decline toward shorter wavelengths is more pronounced in the nickel than in the iron, as expected [Gaffey, 1974]. The two nickel-iron alloys
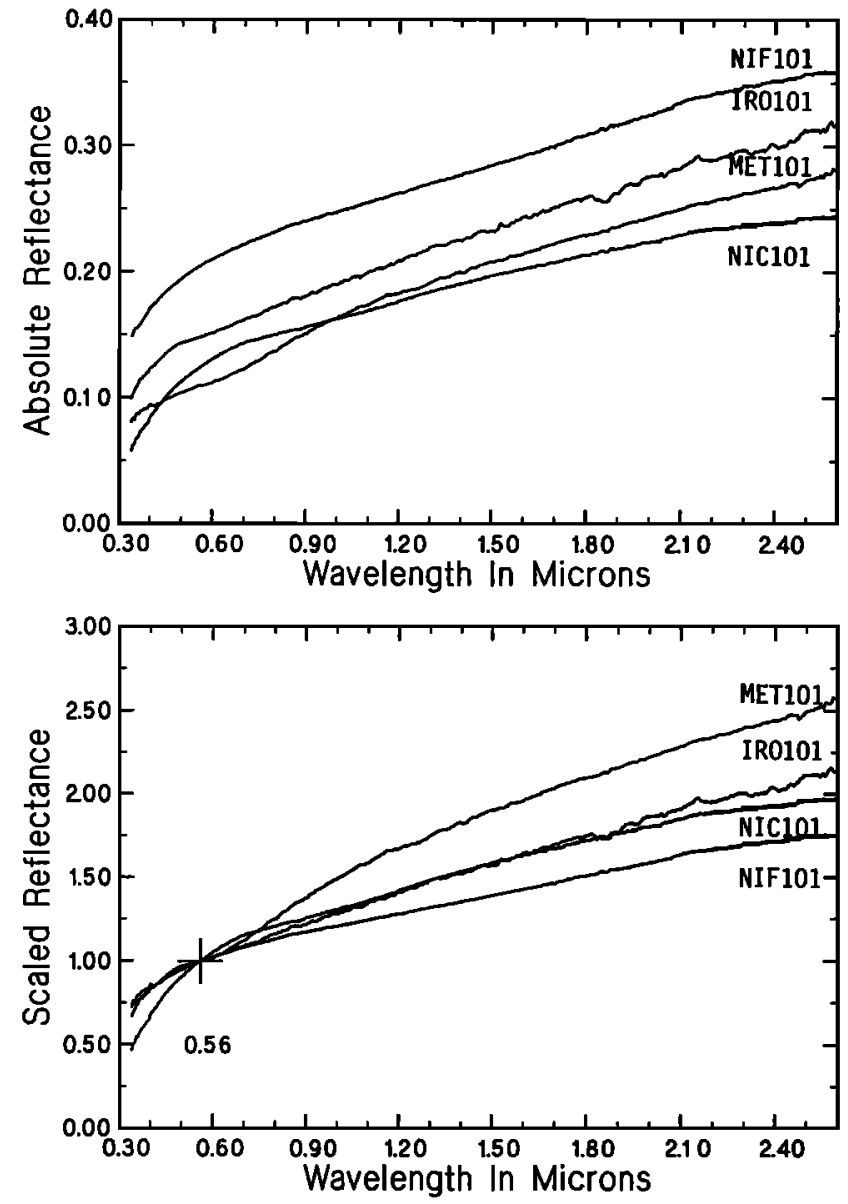

Fig. 1. Absolute (top) and normalized (bottom) reflectance spectra of various small-sized metal powders, nickel (NIC101, <37 $\mu \mathrm{m}$ size), iron (IRO101, <63 $\mu \mathrm{m}$ size), 50:50 prealloyed iron:nickel powder (NIF101, $<63 \mu \mathrm{m}$ size), and meteoritic metal (MET101b, 45-90 $\mu \mathrm{m}$ size). The normalized spectra are scaled to 1 at $0.56 \mu \mathrm{m}$.
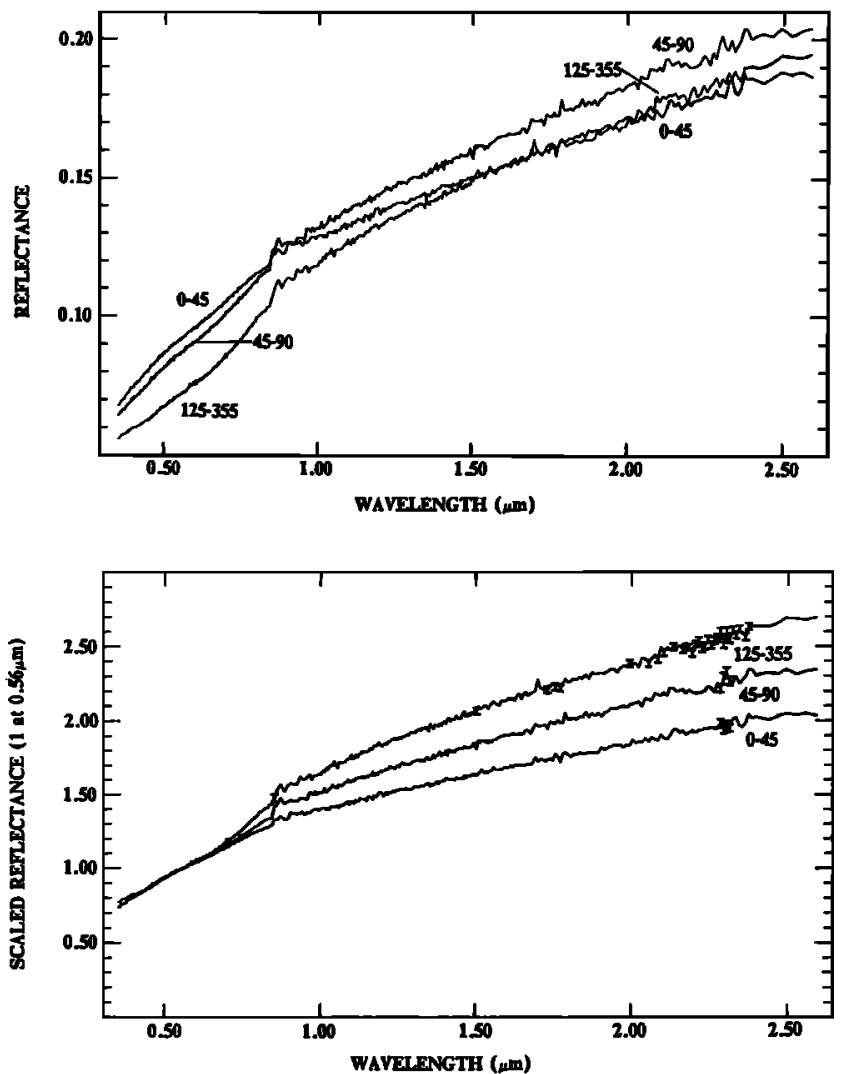

Fig. 2. Absolute (top) and normalized (bottom) teflectance spectra of various sizes of the Odessa octahedrite powdered sample. Grain size ranges are indicated for each spectrum. The normalized spectra are scaled to 1 at $0.56 \mu \mathrm{m}$.

(NIF101, MET101) are not intermediate between the two end-members, suggesting that free electron densities, which affect spectral reflectance, are sensitive to crystallographic structure. No simple correlation exists between reflectance ratios and iron:nickel abundances. Different metals all show the red slope, but meteoritic metal is probably the best material for comparison with the reflectance spectra of metal-rich asteroids.

The effects of grain size variations on metal spectra are illustrated in Figure 2. The different size samples of MET101 are metal shavings; hence spectral differences may not be as extreme as would be present for samples containing more equidimensional particles. Increasing the grain size results in a reduction in albedo at shorter wavelengths. At longer wavelengths the increase in reflectance with increasing wavelength (red slope) is less for the finer-grained than the coarse-grained sample spectra, resulting in crossovers in absolute reflectance. Absolute reflectance is then not only a simple function of grain size but also of wavelength. Although every effor was made to minimize exposure of the metal powders to air, the absolute reflectance of the spectra $(4-9 \%$ at $0.56 \mu \mathrm{m})$ is low compared to other reflectance spectra of iron meteorite powders, slabs, and roughened surfaces, where absolute reflectances of up to $29 \%$ at $0.56 \mu \mathrm{m}$ have been measured [Johnson and Fanale, 1973, Gaffey, 1976; Britt and Pieters, 1988]. The reason for the large range in absolute albedos appears to be a complex function of grain size, sample preparation, and viewing geometry [Britt and Pieters, 1988].

The normalized reflectance spectra of the metal powders (Figure 2) show that the relative increase in reflectance with 
increasing wavelength is greatest for the largest grain sizes. The $1.6 \mu \mathrm{m} / 0.56 \mu \mathrm{m}$ reflectance ratio was selected to examine these changes in overall slope. For the metal powde- spectra presented in Figure 2, this reflectance ratio increases from 1.66 to 2.12 with increasing grain size. Other investigators have measured $1.6 \mu \mathrm{m} / 0.56 \mu \mathrm{m}$ reflectance ratios of between 1.22 and 1.65 , but again, there is no simple dependency between this ratio and grain size or surface roughness dimensions of the samples. For metal slabs with surface roughness dimensions that are roughly equal to, or less than, the wavelength of ligit, the $1.6 \mu \mathrm{m} / 0.56 \mu \mathrm{m}$ reflectance ratio may be less than one [Britt and Pieters, 1988].

Metal powders, as opposed to slabs, have been used for a number of reasons. The principal meteoritic metal phase in almost all iron meteorites and achondrites is kamacite, whose brittle-ductile transition temperature is approximately equal to the temperatures present in the main asteroid belt, and hence may be subject to comminution during impacts [Auten, 1973; Marcus and Hackett, 1974; Remo and Johnson, 1975; Matsul and Schultz, 1984]. The presence of various exsolved and included phases in iron meteorites such as schreibersite/rhabdite, troilite, graphite, and cohenite [Baldanza and Pialla, 1969; Comerford, 1969; Doan and Goldstein, 1969; Buchwald, 1975] may serve as zones of structural weakness and facilitate comminution. Laboratory studies of high-velocity impacts on meteoritic metal show the development of irregular surfaces and spallation products even at temperatures well within the ductile deformation regime [Matsul and Schultz, 1984; Britt and Pieters, 1988].

Iron meteorites contain variable amounts of other minerals such as schreibersite, graphite, troilite, and silicates [Buchwald, 1975]. Amorphous carbon is obviously not spectrally equivalent to these materials but can serve to determine how a small amount of a spectrally distinct opaque phase affects metal spectra. The reflectance spectrum of a $99.5 / 0.5 \mathrm{MET} / \mathrm{LCA}$ mixture can be compared to the pure metal spectrum (Figure 3). The overall reflectance of the mixture spectrum is less than one half that of the metal. The relative degree of redness of the metal spectrum is not affected by the presence of a very dark, opaque phase at this abundance level. A further implication is that the small amount of carbon found in ordinary chondrites is probably not the cause of the flat slope of the metal-rich fraction [Gaffey, 1986].

Reflectance spectra of meteoritic metal+mafic silicat mixtures were measured in order to determine what minimum abundance of silicate is required to be spectrally resolvable. The most metal-rich assemblages measured were $75 / 25$ wt $\%$ mixtures of metal/olivine and metal/pyroxene. At these abundances, olivine is barely resolvable as a narrow reflectance plateau near $1 \mathrm{\mu m}$ superimposed on the red metal slope, while the metal+pyroxene mixture retains two clearly resolved absorption bands (E.A. Cloutis et al., submitted manuscript, 1989). Some metal- and olivine-rich meteorites, such as Glorieta Mountain and Newport, contain $<25 \mathrm{wt} \%$ olivine [Buseck, 1977]. The parent bodies of these objects may be almost indistinguishable from iron meteorite-like bodies on the basis of their reflectance spectra. The olivine contents of the vast majority of the pallasites are high enough to suggest that olivine absorption bands should be resolvable, and metal- and olivine-rich asteroids have, in fact, been identified [Bell et al., 1984; Crulkshank and Hartmann, 1984]. Metal- and pyroxene-rich asteroids similar to mesosiderites and siderophyres will be easier to identify because the minimum threshold for detecting ferrous iron-bearing pyroxene is $-10 \mathrm{wt}$ $\%$.
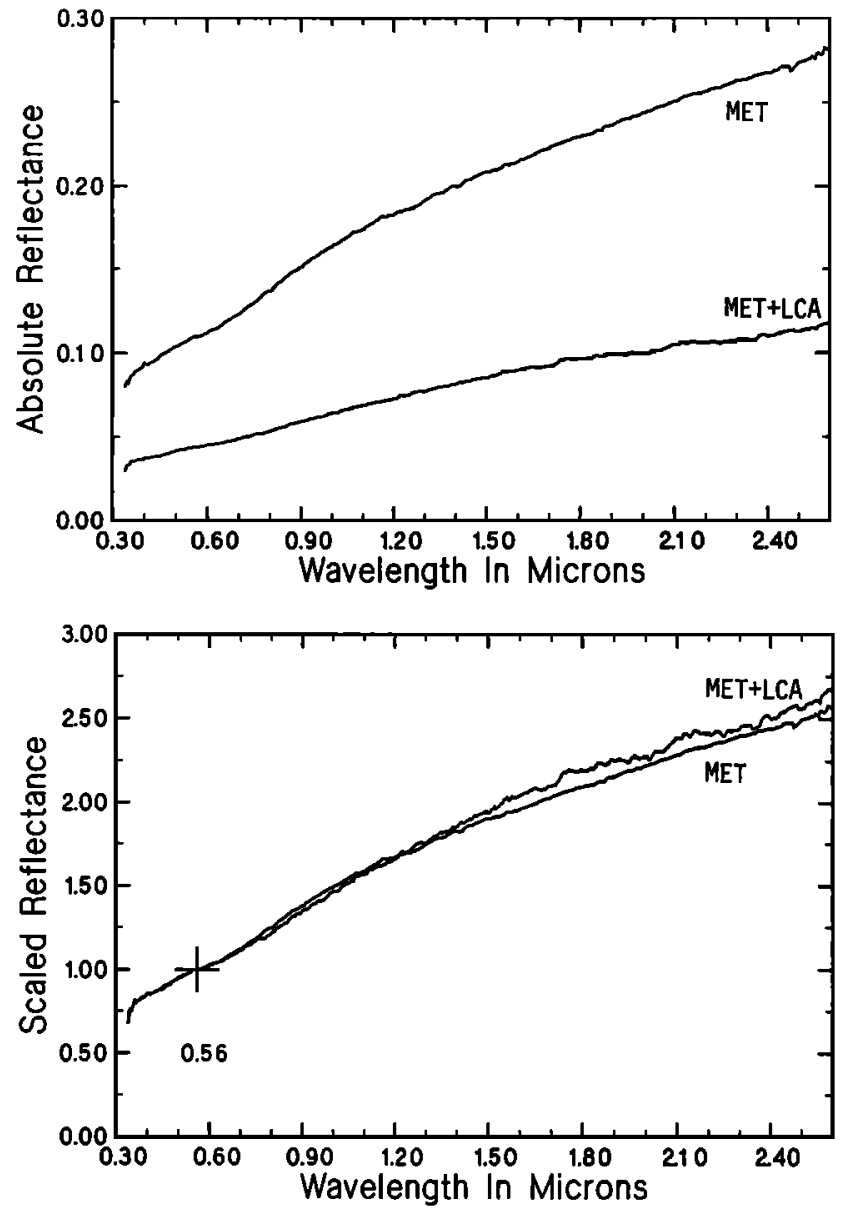

Fig. 3. Absolute (top) and normalized (bottom) reflectance spectra of 45-90 $\mathrm{\mu m}$ beaten meteoritic metal (MET101), and a 99.5/0.5 wt \% mixture of meteoritic metal/amorphous carbon (MET101/LCA101). The normalized spectra are scaled to 1 at $0.56 \mu \mathrm{m}$.

\section{Silicates: Enstatite}

Very low-iron content enstatite $(<1 \% \mathrm{FeO})$ is the most abundant mineral in enstatite chondrites and aubrites [Mason, 1966; Kell, 1968; Watters and Prinz, 1979]. Aubrites are nearly pure enstatite with almost no carbon [Grady et al., 1986]. Their mineralogy is approximately $75.98 \%$ enstatite, $0.16 \%$ plagioclase, $0-8 \%$ diopside, $0-10 \%$ olivine, $0-4 \%$ metal, and 0-7\% troilite [Olsen et al., 1977; Watters and Prinz, 1979; Watters et al., 1980]. Enstatite chondrites differ from enstatite achondrites primarily by their higher opaque contents $(22-33$ wt \% metal+troilite [Keil, 1968]).

Spectrally, enstatite shows no well-resolved absorption features because of the almost complete absence of transition series elements. The reflectance spectrum of the Happy Canyon acid-insoluble fraction is flat to within $2 \%$ with a slight downturn in reflectance at wavelengths less than $-0.4 \mu \mathrm{m}$ and a weak absorption band near $0.9 \mu \mathrm{m}$ (Figure 4). The weak absorption band near $1.9 \mu \mathrm{m}$ is probably due to the presence of a small amount of a hydrated phase. This contrasts with meteoritic metal, the second most abundant phase in enstatite chondrite, which has a red slope even when the metal is finely comminuted (Figure 2). There is little chance of confusing the reflectance spectra of metal and enstatite.

\section{Enstatile +Metal}

Although the reflectance spectra of enstatite + metal mixtures have not been measured in this study, they can be deduced 


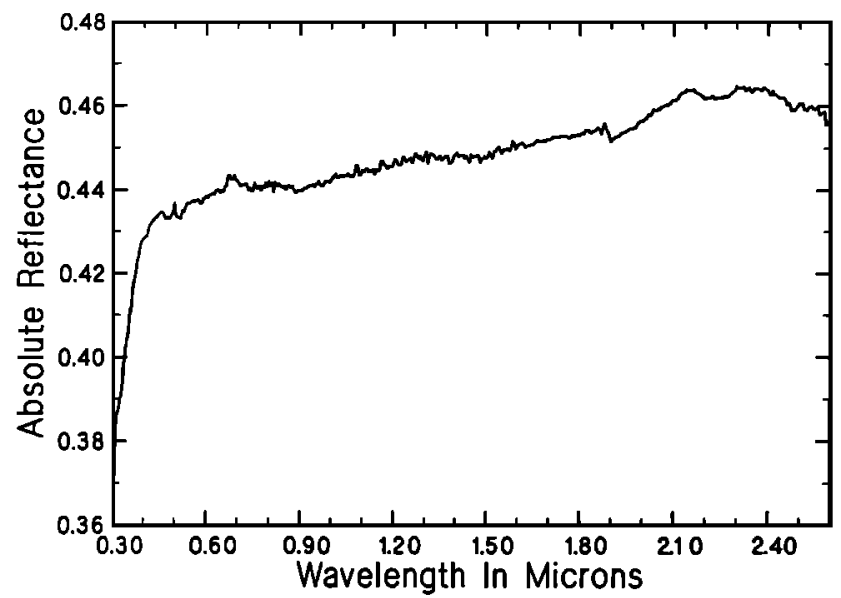

Fig. 4. Absolute reflectance spectrum of the 45- to $90-\mu \mathrm{m}$-sized acid-insoluble fraction of the Happy Canyon E7 enstatite chondrite.

from the reflectance spectra of enstatite chondrites. These meteorites are composed predominantly of enstatite and metal [Ketl, 1968], and their spectral slopes are transitional between pure metal and pure enstatite [Salisbury and Hunt, 1974; Salisbury et al., 1975; Gaffey, 1976; Dollfus et al., 1980; Mi yamoto, 1987]. Some enstatite chondrite spectra show a slope break near $0.6 \mu \mathrm{m}$ whose cause is uncertain. The average grain size of the metal is $<30 \mu \mathrm{m}$ in lower petrologic grades increasing to $\sim 50 \mu \mathrm{m}$ in higher grades [Easton, 1983]. It is reasonable to use the $<45-\mu \mathrm{m}$-sized meteoritic metal for investigating the spectral properties of enstatite chondrites.

The $1.8 \mu \mathrm{m} / 0.7 \mu \mathrm{m}$ reflectance ratio was selected to highlight spectral slope differences between the aubrites, enstatite chondrites, and iron meteorites. This portion of the spectrum is roughly linear in all three groups and avoids the ultraviolet-visible spectral region which can be strongly affected by intense charge transfer absorptions in accessory phases which are not diagnostic of a specific mineralogy. A plot of the $1.8 \mu \mathrm{m} / 0.7 \mu \mathrm{m}$ reflectance ratio of the available meteorite spectra versus the nonsilicate content of the meteorites shows a roughly linear correlation with the notable exception of Abee (Figure 5). The increased red slope of this meteorite is likely due differences in sample preparation. Other spectra of Abee and another low-grade enstatite chondrite (Y-691) show a much flatter slope [Salisbury and Hunt, 1974; Salisbury et al., 1975; Mi yamoto, 1987] which is more in line with the E6 chondrites. The $2.5 \mu \mathrm{m} / 0.6 \mu \mathrm{m}$ reflectance ratio of Abee is variously -1.2 [Salisbury and Hunt, 1974], 1.56 [Salisbury et al., 1975], and 1.69 [Gaffey, 1976]. This ratio is mentioned only because, unlike the $1.8 \mu \mathrm{m} / 0.7 \mu \mathrm{m}$ ratio, it is available for all the various spectra of Abee. Other low-petrologic grade enstatite chondrites have $2.5 \mu \mathrm{m} / 0.6 \mu \mathrm{m}$ ratios of 1.28 (Yamato 691 [Miyamoto, 1987]) and 1.56 (Indarch [Salisbury et al., 1975]). Regardless of the cause of the excess reddening of one Abee spectrum, the $1.8 \mu \mathrm{m} / 0.7$ $\mu \mathrm{m}$ ratio of Abee (1.37) from Gaffey [1976] is less than the fine-grained pure metal (1.55).

The lower petrologic grade enstatite chondrites have more diverse silicate compositions than the higher grades, with a few percent of the mafic silicates containing appreciable amounts of iron [Lusby et al., 1987]. The lower petrologic grade sample spectra should show some evidence of mafic silicate absorption bands, a less red slope, and a higher overall albedo than the more equilibrated meteorites on the basis of metal grain size differences and compositional heterogeneity of the silicates.

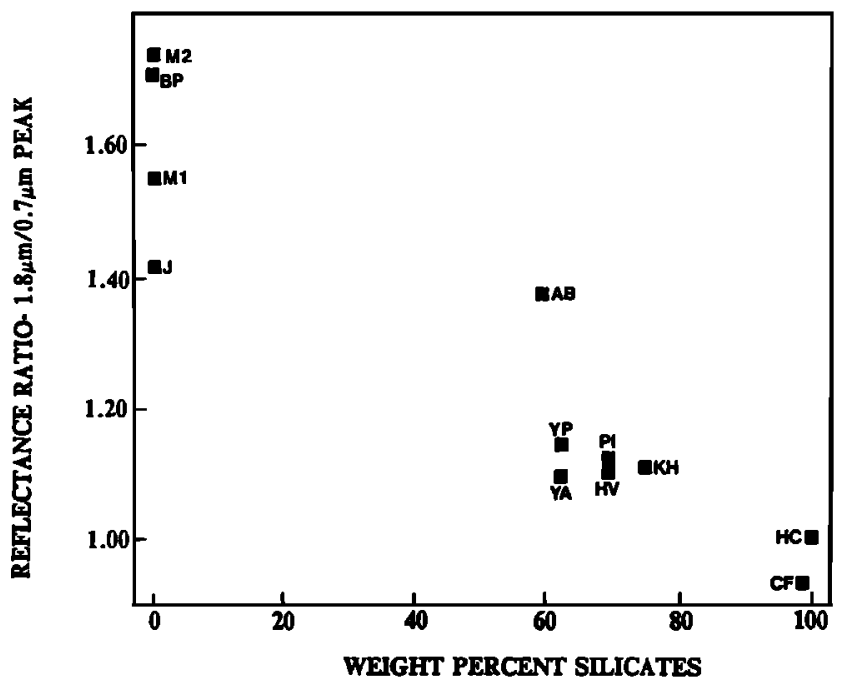

Fig. 5. Plot of the $1.8 \mu \mathrm{m} / 0.7 \mu \mathrm{m}$ reflectance ratio versus the silicate abundance for the iron meteorite (MET101), acid-insoluble fraction of the Happy Canyon enstatite chondrite and various aubrites and enstatite chondrites from the literature. M1, MET101:<45 $\mu \mathrm{m} ; \mathrm{M} 2$, MET101:45-90 $\mu \mathrm{m}$ (this study); J, Odessa [from Johnson and Fanale, 1973]; AB, Abee; CF, Cumberland Falls; HV, Hvittis; KH, Khairpur; PI, Pllistfer [from Gaffey, 1974, 1976]; YP, Yamato-691 plate; YA, Yamato-691 powder [from Miyamoto, 1987]; BP, $10 \mu \mathrm{m}$ to $1 \mathrm{~mm}$ size iron meteorite filings [from Britt and Pleters, 1988].

The available reflectance spectra show that the lower petrologic grade specimens exhibit variable evidence of mafic silicate absorption bands, a more red slope, and a lower overall albedo [e.g., Sallsbury et al., 1975]. The increased red slope of the lower grades may be due to the more efficient dispersal of metal throughout the matrix due to its smaller grain size [Easton, 1983], the presence of both oxidized and unoxidized metal grains, versus the higher petrologic grade meteorites [Gaffey, 1986], or differences in sample preparation. Some of the spectra show weak absorption features which may be due to minor amounts of iron-bearing silicates (Figure 4)[Gaffey, 1976; Mlyamoto, 1987]. Additional spectral complexities will appear if the mineralogy of enstatite-rich bodies is more diverse than previously believed [Grossman et al., 1988].

\section{Carbon}

A series of carbon-mafic silicate and magnetite-mafic silicate mixtures was spectrally characterized. Only the most opaquerich samples are dealt with here, as the intention is to establish spectral detection limits for the mafic silicates. Carbon is present in varying amounts and forms in all chondritic meteorites and the ureilites. Its abundance and form will determine the degree to which the mafic silicates are resolvable. The most carbon-rich meteorite classes are the ureilites (2-5 wt \%) and the carbonaceous chondrites (0.1-5 wt \%) [e.g., Gibson et al., 1971; Glbsnn, 1976]. The carbon is largely in the form of submicron, dispersed grains, commonly with an amorphous or semiamorphous structure [Vdoyykin, 1970; Bauman et al., 1973; Van Der Stap et al., 1986; Blake et al., 1988]. Fine-grained amorphous carbon was chosen as a worst case spectral scenario, a highly absorbing, dispersable material. This material has a slightly blue overall slope with an average reflectance of $<1 \%$ (Figure 6 ).

The lowest mafic silicate:carbon ratio measured was 98:2, which is in the midrange of the carbonaceous chondrites and ureilites. At this abundance, carbon greatly reduces the spectral 

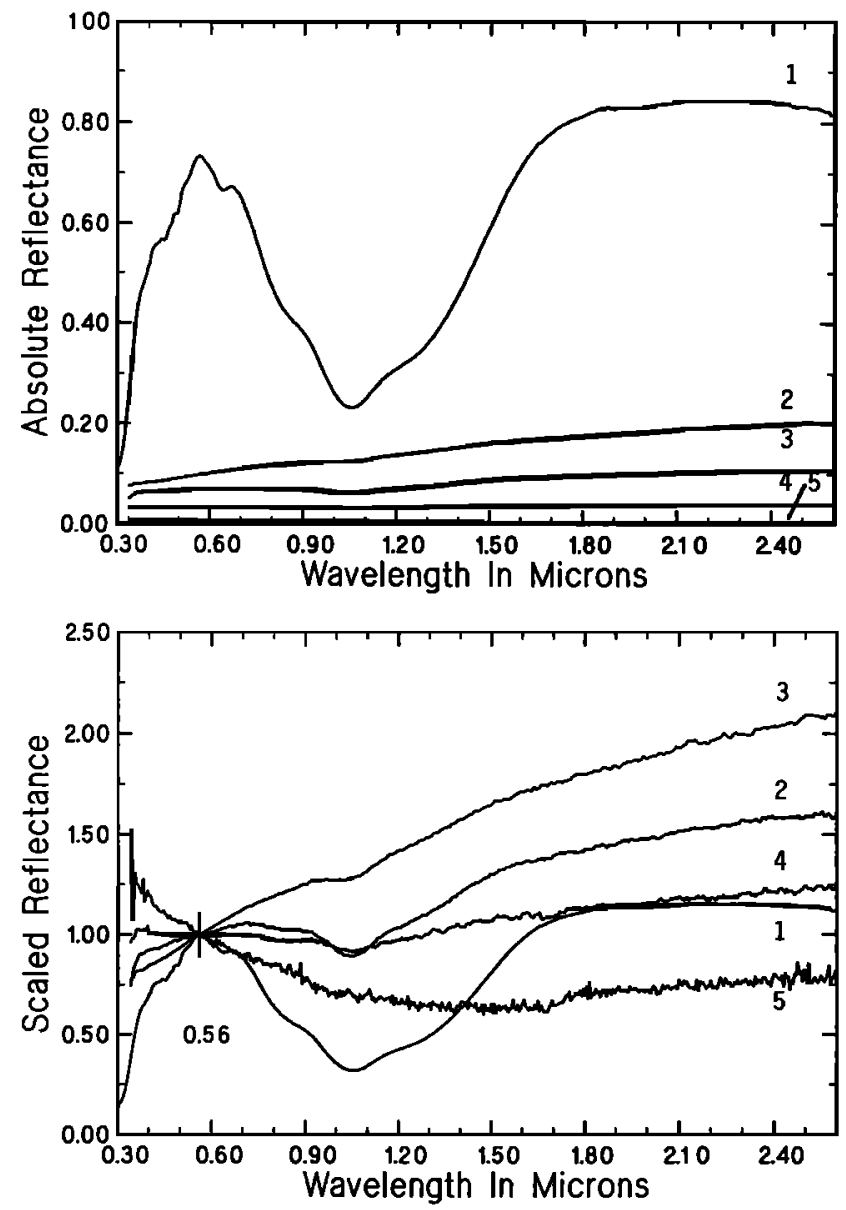

Fig. 6. Absolute (top) and normalized (bottom) reflectance spectra of various mixtures of olivine (OLV003) and amorphous carbon (LCA101) Olivine/carbon weight percentages: $1,100 / 0 ; 2,99.5 / 0.5 ; 3,99.5 / 0.5 ; 4$, $98 / 2 ; 5,0 / 100$. Sample 3 contans $<45-\mu \mathrm{m}-$ sized olvvine. All other samples contain $45-$ to $90-\mu \mathrm{m}$-sized olivine. The normalized spectra are scaled to 1 at $0.56 \mu \mathrm{m}$.

reflectance of the olivine (Figure 6) and pyroxene (Figure 7), but their major $\mathrm{Fe}^{2+}$ absorption bands are still resolvable. The effect of mafic silicate grain size on the detection limit was investigated for the olivine. A 99.5:0.5 by weight olivine:carbon mixture using $<45-\mu \mathrm{m}$ sized olivine has a reflectance spectrum with an almost completely obscured $1-\mu \mathrm{m}$ absorption band. The mixture containing the same proportions but with a 45 - to $90-\mu \mathrm{m}$ sized olivine has a well-defined 1- $\mu \mathrm{m}$ absorption band (Figure 6).

An overall red slope is introduced to the mafic silicate spectrum by the carbon. This seems to be a common feature in mafic silicate-amorphous carbon mixtures [Miyamoto et al., 1981, 1982]. A similar reddening is seen in the spectra of the finest fractions of carbonaceous chondrites, perhaps due to the more effective dispersal of the opaque phase [Johnson and Fanale, 1973]. The redness seems to diminish at higher carbon abundances. An opposite effect (blue slope) is seen in fine-grained mixtures of montmorillonite-carbon, even though both phases are slightly red [Clark, 1983].

The spectral effect of adding carbon to a mafic silicate is to reduce the overall albedo, but major absorption bands remain resoivable. Although no more than $2 \mathrm{wt} \%$ carbon was used, the available data for the carbon-silicate mixtures suggest that olivine and pyroxene absorption bands may be resolvable up to 5-6 wt \% carbon if the silicates retain a mean grain size in the

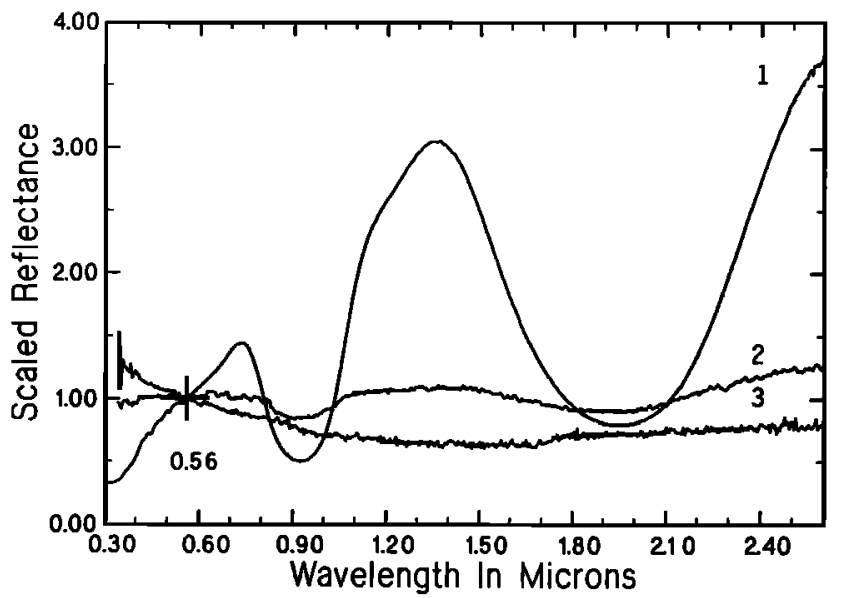

Fig. 7. Normalized reflectance spectra (scaled to 1 at $0.56 \mu \mathrm{m}$ ) of mixtures of pyroxene (PYX032) and amorphous carbon (LCA101). The weight percentages of pyroxene/carbon and absolute reflectances at $0.56 \mu \mathrm{m}$ are $1,100 / 0,0.080 ; 2,98 / 2,0.017 ; 3,0 / 100,0.0076$.

tens of microns range. For finer-grained materials the detection limit is substantially lower, perhaps 1-2 wt \% carbon. It would appear that the parent bodies of the carbon-rich meteorites should be identifiable by the presence of weak mafic silicate absorption bands, or if the silicates are finely comminuted, by a red spectral slope of low albedo, assuming that amorphous carbon is spectrally equivalent to meteoritic carbon. Reexamination of dark meteorite spectra has shown that $\mathrm{Fe}^{2+}$ silicate absorption features are more widespread than expected [Gaffey, 1978, 1980; Vilas and Gaffey, 1989]. Dark, flat reflectance spectra cannot be attributed to the presence of amorphous carbon alone if the host materials consists of mafic silicates. The carbon must be in some other structural form or an additional opaque phase must be present.

The enstatite chondrites contain a small amount $(0.25-0.5 \mathrm{wt}$ \%) of carbon [Moore and Lewis, 1965; Grady et al., 1986], with the lower abundances in the higher petrologic grades. The carbon is largely in the form of graphite, cohenite, and other unspecified forms [Kell, 1968; Deines and Wickman, 1985] and is more ordered in the higher petrologic types [Grady et al., 1986]. This amount of carbon should not affect the overall reflectance slope.

\section{Iron Oxides}

Magnetite is the other opaque phase which is most prevalent in carbonaceous chondrites. A series of olivine-magnetite mixtures have been spectrally characterized to conf $1 \mathrm{rm}$ that magnetite-mafic silicate mixtures have dark, relatively flat reflectance spectra [Singer, 1981; Mi yamoto et al., 1982]. At the highest magnetite abundance measured, 50/50 magnetite/ olivine both $45-90 \mu \mathrm{m}$ size, the $\mathrm{Fe}^{2+}$ absorption band is still clearly resolvable (Figure 8). Coarse-graned magnetite is clearly not a viable candidate for the darkening agent in carbonaceous chondrites and $\mathrm{C}$-class asteroids. Fine-grained magnetite imparts a much bluer slope to the reflectance spectrum but the absorption feature near $1 \mu \mathrm{m}$ is still clearly resolvable. Fine-grained magnetite alone is not sufficient to account for the low contrast or lack of mafic silicate absorption bands in carbonaceous chondrites and $\mathrm{C}$-class asteroids but in combination with carbon can probably provide all the necessary spectral modifications. Ternary carbon-magnetite-mafic silicate spectra remain to be measured and were not included in this study. 

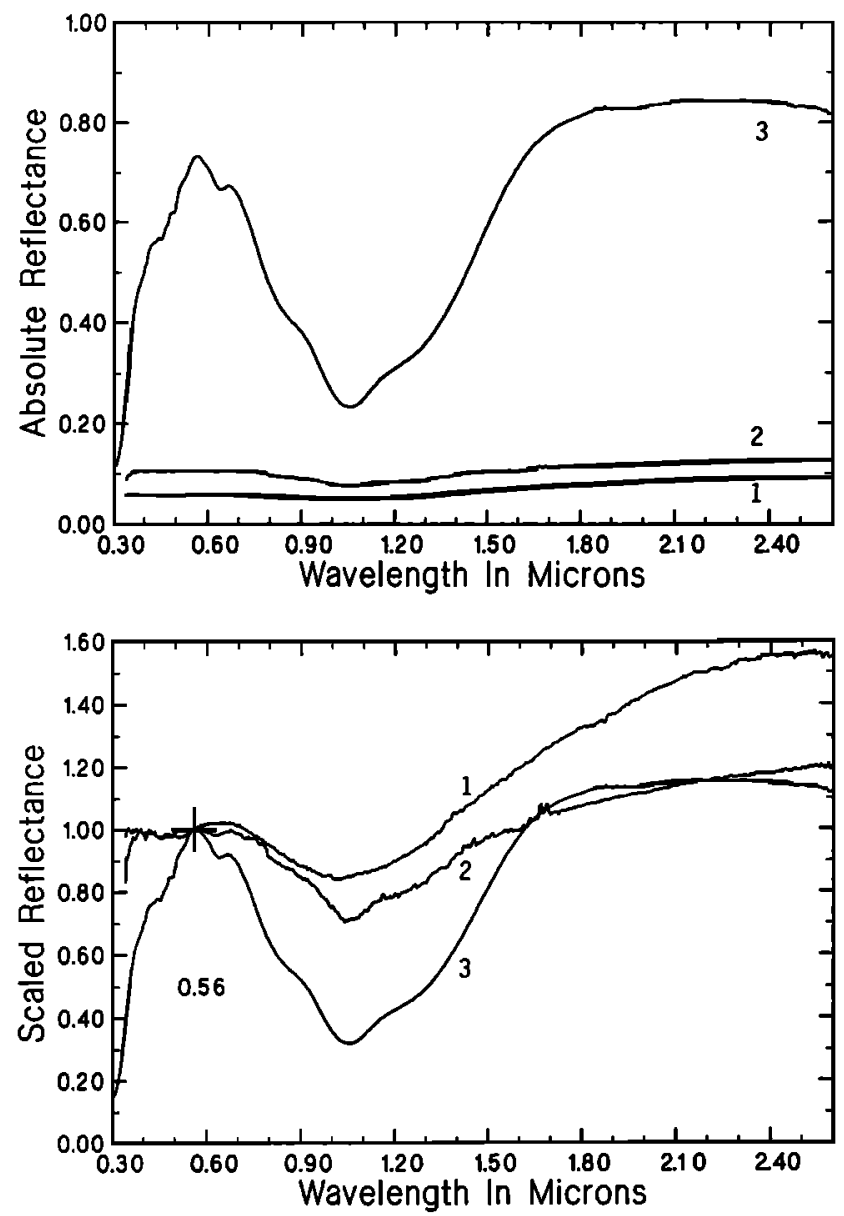

Fig. 8. Absolute (top) and normalized (bottom) reflectance spectra of 1, olivine (OLV003, 45-90 $\mu \mathrm{m}$ size); 2, magnetite (MAG101, 45-90 $\mu \mathrm{m}$ ); and 3, a $50 / 50$ mixture of the two. The normalized spectra are scaled to 1 at $0.56 \mu \mathrm{m}$.

A 45- to $90-\mu \mathrm{m}$ sized magnetite has been used in most cases, although the bulk of the magnetite in carbonaceous chondrites is much finer grained [e.g., Kerridge, 1970]. Magnetite reflectance spectra show a reflectance maximum near $0.8 \mu \mathrm{m}$ and a weak absorption band near $1 \mu \mathrm{m}$ [Hunt et al., 1971a; Adams, 1975; Gradie and Veverka, 1980; Singer, 1981; Wagner et al., 1987]. Beyond $1 \mu \mathrm{m}$ the spectrum may remain constant, decline slightly or increase slightly. The absence of a reflectance increase seems to be characteristic of cation-deficient and fine-grained specimens [Morris et al., 1985]. The magnetite in carbonaceous chondrites is fine-graned and probably not stoichiometric $\mathrm{Fe}_{3} \mathrm{O}_{4}$ [Kerridge, 1970; Nagy, 1975]. The magnetite spectra of Morris et al. [1985] are probably the most reasonable spectral analogues for the magnetite in carbonaceous chondrites.

\section{Application to Asteroid Spectra}

The spectral detection limits for mafic silicates mixed with various featureless materials depend on a number of factors. Particle size, mineral chemistry, degree of dispersion, and abundance are all significant parameters. This complicates interpretation of the reflectance spectra of dark, nearly featureless objects. The situation for enstatite and metal is more straightforward. A representative member of the $M$ - and $E$-class asteroids was selected for reanalysis in light of the laboratory results reported here.

\section{M-Class Asterotd (16) Psyche}

Asteroid (16) Psyche has been variously interpreted as possessing either an iron meteorite-like surface assemblage [Johnson and Fanale, 1973; Dollfus et al., 1979; Ostro et al., 1985] or an enstatite chondrite-like surface assemblage [Chapman and Salisbury, 1973; Chapman, 1976]. The 0.3- to $1.1-\mu \mathrm{m}$ reflectance spectrum of Psyche [Gaffey and McCord, 1978] shows a gradual increase in reflectance toward longer wavelengths with a weak, broad absorption feature near $0.6 \mu \mathrm{m}$ and a weak, narrow absorption feature near $0.9 \mu \mathrm{m}$. The 52-color asteroid survey spectrum [Bell et al., 1988] covers the wavelength range from $0.8 \mu \mathrm{m}$ to $2.5 \mu \mathrm{m}$ and shows no other well-defined absorption bands (Figure 9). The competing interpretations of the surface assemblage of Psyche have been based largely on the overall slope of the reflectance spectrum.

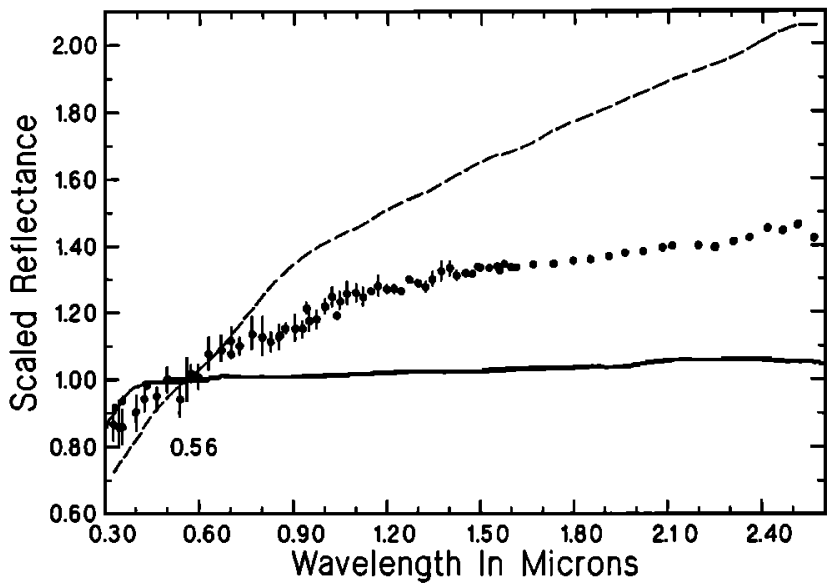

Fig. 9. Normalized refı ctance spectra (scaled to 1 at $0.56 \mu \mathrm{m}$ ) of the $<45-\mu \mathrm{m}$-sized meteoritic metal, MET101 (dotted line), the acid-insoluble fraction of the Happy Canyon enstatite chondrite (line). and asteroid (16) Psyche (points)[Gaffey et al., 1988].

The $1.6 \mu \mathrm{m} / 0.56 \mu \mathrm{m}$ and $2.2 \mu \mathrm{m} / 0.56 \mu \mathrm{m}$ reflectance ratios for Psyche [Veeder et al., 1978; Larson and Veeder, 1979; Gaffey et al., 1988], enstatite chondrites, aubrites [Gaffey, 1976; Mi yamoto, 1987], iron meteorite slabs and powders [Johnson and Fanale, 1973; Gaffey, 1976; Britt and Pleters, 1988], and the acid-insoluble fraction of the Happy Canyon E7 chondrite are shown in Figure 10. The reflectance ratios for Psyche fall well within the enstatite chondrite field. Even the finest-grained metal spectrum ( $<45 \mu \mathrm{m}$ size), which has a mean grain size similar to that derived for Psyche on the basis of polarimetry [Dollfus et al., 1979] is significantly redder than Psyche. The absolute reflectance of Psyche $(9-11 \%$ at $0.56 \mu \mathrm{m})$ is not diagnostic of a particular assemblage. The available enstatite chondrite spectra have absolute reflectances at 0.56 $\mu \mathrm{m}$ of between 8 and $18 \%$, while for iron meteorites the absolute reflectance ranges from 7 to $29 \%$. Variations in particle size and the presence of opaque, but spectrally neutral accessory phases would increase the ranges of absolute reflectance of enstatite chondrites and metal. This is in addition to the uncertainties in absolute albedo due to the differences between laboratory and telescopic reflectance spectra [Hapke, 1981].

The 0.3 - to $2.6-\mu \mathrm{m}$ normalized reflectance spectrum of Psyche is shown overlain with the normalized reflectance spectra of the Happy Canyon sample and the 45- to $90-\mu \mathrm{m}$-sized iron meteorite powder (Figure 9). The asteroid spectrum is intermediate between the two laboratory spectra 


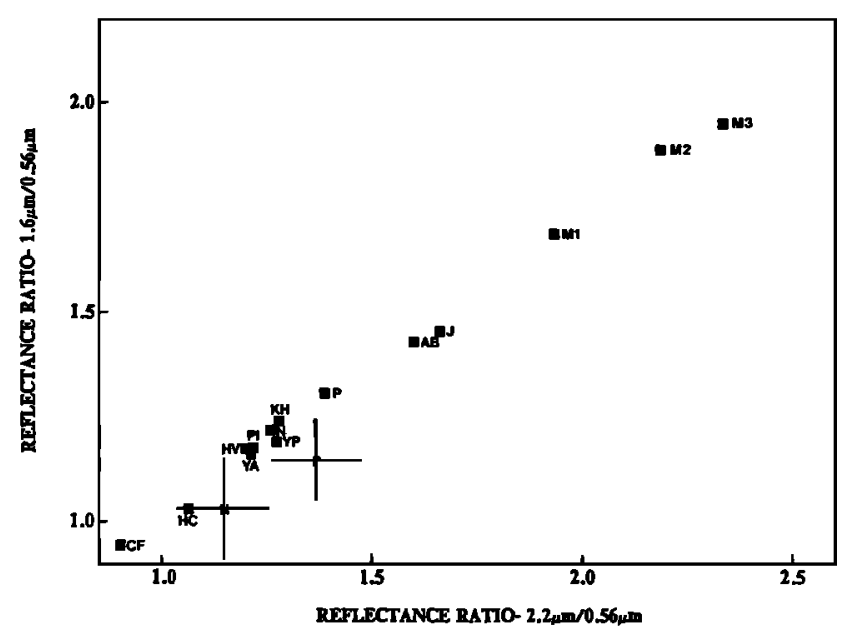

Fig. 10. Plot of the $1.6 \mu \mathrm{m} / 0.56 \mu \mathrm{m}$ reflectance ratio versus the 2.2 $\mu \mathrm{m} / 0.56 \mu \mathrm{m}$ reflectance ratio for the various enstatite- and metal-rich meteorites. M3, MET101 $125-$ to $355-\mu \mathrm{m}$ grain size; other symbols are the same as in Figure 5. The average values and error bars are also shown for the asteroids Psyche (P), and Nysa (N) [from Veeder et al., 1978; Gaffey et al., 1988].

and exhibits a change in slope near $1 \mu \mathrm{m}$. The reason for this slope change is not known, but it appears to varying degrees in the iron meteorite powder spectra and is most apparent for the finest grain size spectrum. A similar change in slope is present in many of the enstatite chondrite spectra but occurs near 0.7 $\mu \mathrm{m}$ in these cases [Gaffey, 1974, 1976]. This suggests that enstatite chondrite and metal spectra may be distinguishable on the basis of the wavelength position of the slope change. On this basis, Psyche is similar to the iron meteorite spectra. The slopes of the iron meteorite spectra on either side of the $1-\mu \mathrm{m}$ inflection decrease with decreasing grain size. The slopes for Psyche (as measured by the $1.0 \mu \mathrm{m} / 0.35 \mu \mathrm{m}$ and $2.5 \mu \mathrm{m} / 1.0$ $\mu \mathrm{m}$ reflectance ratios) are less than for the $<45 \mu \mathrm{m}$-sized metal but fall along a trend for the metal powders, suggesting that if the surface of Psyche is composed predominantly of metal, a significant portion of this metal is extremely fine grained (Figure 11).

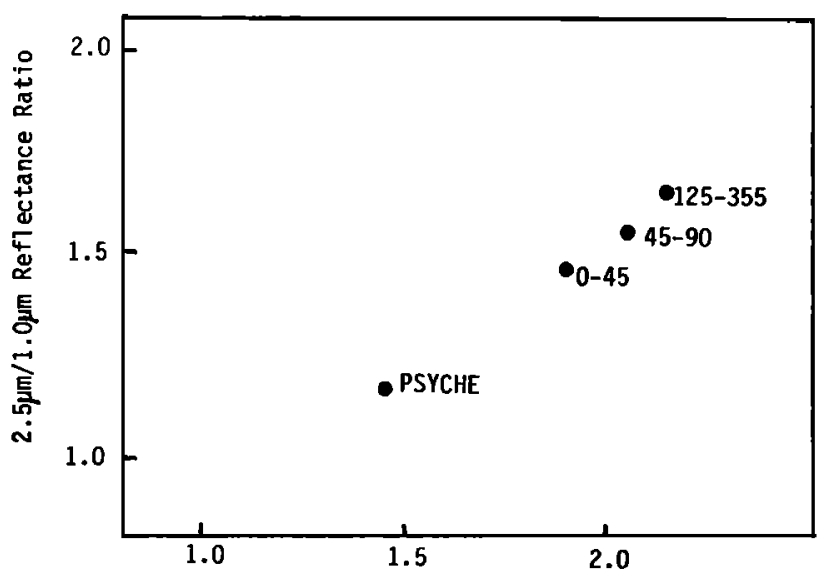

1.0 $\mathrm{m} / 0.35 \mathrm{~mm}$ Reflectance Ratio

F1g. 11. $2.5 \mu \mathrm{m} / 1.0 \mu \mathrm{m}$ versus $1.0 \mu \mathrm{m} / 0.35 \mu \mathrm{m}$ reflectance ratios for the various MET101 iron meteorite powders and asteroid (16) Psyche. The numbers indicate the grain size range of the powders $(\mu \mathrm{ri})$.
The polarimetric values $P_{\min }$ and $V_{0}$ (or $\alpha_{0}$ ) for enstatite chondrites plot outside the range for metal powders and $M$ asteroids with the exception of the E4 chondrite, Abee [Dollfus et al., 1971; Zellner, 1975; Zellner et al., 1977a,b; Dollfus et al., 1979]. The reason for this discrepancy may be related to the fact that the Abee powdered sample was obtained from a cut slab, whereas the other enstatite chondrite samples were obtained from broken pieces. Saw cut chondrites are visibly different from broken surfaces because cutting a meteorite exposes the interior of metal grains which are otherwise not seen on broken surfaces [Gaffey, 1986]. It is possible that this may also have an effect on the polarimetric properties of the sample.

The polarimetric data for metal powders suggest that the surface of Psyche possesses predominantly fine-grained metal particles of $-20 \mu \mathrm{m}$ size [Dollfus et al., 1979]. A fine-grained surface would also be in agreement with the radar albedo data suggesting a predominantly metallic surface of fine-grained particles with lunar regolith-like porosities [Ostro et al., 1985]. A reduction in metal content must be accompanied by a reduction in porosity in order to reconcile with the radar data.

The weak absorption bands seen in Psyche's reflectance spectrum are not particularly diagnostic. The reflectance spectrum of Psyche shows broad absorption features near 0.6 and $0.9 \mu \mathrm{m}$. The broad absorption near $0.6 \mu \mathrm{m}$ is also seen in some meteoritic metal spectra (Figure 2)[Dollfus et al., 1980], in troilite [Egan and Hilgeman, 1977], and in Abee [Gaffey, 1976; Dollfus et al., 1980]. It does not appear to be uniquely characteristic of a particular phase.

The weak feature near $0.9 \mu \mathrm{m}$ is not characteristic of metal, but a similar feature is seen in the $\mathrm{E} 7$ reflectance specrum (Figure 4), other enstatite chondrites [Gaffey, 1976], and iron sulphides [Hunt et al., 1971b]. It is commonly ascribed to ferrous iron crystal field transitions and could be due to iron in either sulphides or silicates.

The 3- to 4- $\mu \mathrm{m}$ spectrum of Psyche [Eaton et al., 1983] does not show the red slope expected for metal and appears to be even flatter than the available $E$ chondrite spectrum [Miyamoto, 1987]. Fine-grained metal may account for the flatter than expected slope.

The observational data tend to support a fine-grained metal surface assemblage for Psyche, although an enstatite chondrite-like assemblage cannot be conclusively excluded. Minor accessory phases such as troilite are probably the cause of the various weak absorption bands which seem to be present. An iron-bearing mafic silicate component, if present, is constrained to $<20 \mathrm{wt} \%$ by spectroscopic and radar considerations.

\section{E-Class Asterold (44) Nysa}

Asteroid (44) Nysa was selected for analysis because it is the best characterized member of the $E$ class of asteroids. Visible and near-infrared spectra [Chapman and Gaffey, 1979; Bell et al., 1988; Gaffey et al., 1988], inf rared photometry [Veeder et al., 1978], and photopolarimetry [Zellner, 1975; Zellner et al., 1977a] are available for this object.

Nysa is a bright object. Its geometric albedo has been determined to be $-38 \%$ [Zellner, 1975], while the absolute albedo at $0.56 \mu \mathrm{m}$ has been determined to be $-49 \%$ [Gaffey et al., 1988]. The differences can best be ascribed to the different methods used in deriving absolute albedos [e.g., Hapke, 1981]. The high albedo strongly suggests that a transition metal-free silicate such as forsterite, plagioclase feldspar, or enstatite is a dominant surface component. Enstatite is the likeliest 
candidate on the basis of meteoritical evidence. The two main enstatite-rich meteorite groups, enstatite chondrites and aubrites, vary primarily in the amount of metal and sulphides they contain. Enstatite chondrites normally contain 25-30 wt \% metal+troilite versus $<2 \mathrm{wt} \%$ in the aubrites [Keil, 1968; Watters and Prinz, 1979]. The reflectance spectra of these two groups differ in terms of overall reflectance and degree of spectral reddening.

The $1.6 \mu \mathrm{m} / 0.56 \mu \mathrm{m}$ and $2.2 \mu \mathrm{m} / 0.56 \mu \mathrm{m}$ reflectance ratios of Nysa from photometry and spectroscopy fall in or near the field occupied by the aubrites (Figure 10). The 0.56- to $0.35-\mu \mathrm{m}$ wavelength interval for Nysa (Figure 12) shows a $\sim 10 \%$ reflectance decrease, comparable to the aubrites [Gaffey, 1974, 1976] and metal-free Happy Canyon spectrum (Figure 4) but much less than the $-30 \%$ decrease seen in most of the enstatite chondrites and metal (Figure 2)[Gaffey, 1974, 1976; Salisbury et al., 1975; Miyamoto, 1987]. The absolute reflectance of Nysa also suggests a close affinity to the aubrites. The absolute reflectance of aubrites and Happy Canyon at $0.56 \mu \mathrm{m}$ varies between 23 and $44 \%$. For enstatite chondrites the range is $6-18 \%$, even for very fine-grained samples. The difference in absolute reflectance between the Happy Canyon $45-$ to $90-\mu \mathrm{m}$-sized sample spectrum (44\% at $0.56 \mu \mathrm{m})$ and Nysa $(49 \%$ at $0.56 \mu \mathrm{m})$ can be reconciled by decreasing the grain size of the laboratory sample. By analogy to plagioclase, another low transition metal content silicate, a $<25-\mu \mathrm{m}$-sized sample of Happy Canyon would have an absolute reflectance of $-55 \%$ at $0.56 \mu \mathrm{m}$ [Crown and Pieters, 1987]. The reflectance spectrum of Nysa is redder than the Happy Canyon spectrum, but not as red as meteoritic metal (Figure 12). The red slope and the weak absorption bands near $0.9 \mu \mathrm{m}, 1.4 \mu \mathrm{m}$, and 1.8-1.9 $\mu \mathrm{m}$ present in the spectrum of Nysa must be due to some other material because aubritic pyroxene is nearly flat and featureless (Figure 4). The small amounts of metal present in aubrites [Watters and Prlnz, 1979] could conceivably provide a slight red slope to enstatite without drastically reducing overall reflectance. The absorption features present in Nysa's spectrum are weak, with band depths $\left(D_{b}\right.$ [Clark and Roush, 1984]) of 2-3\%.

The wavelength positions of the bands near $0.9 \mu \mathrm{m}(0.905$ $\mu \mathrm{m})$ and $1.8 \mu \mathrm{m}(1.808 \mu \mathrm{m})$ correspond almost exactly with the band positions expected for very low iron $(\mathrm{Fs}=5)$ orthopyroxene but not for low iron olivine, clinopyroxene, or

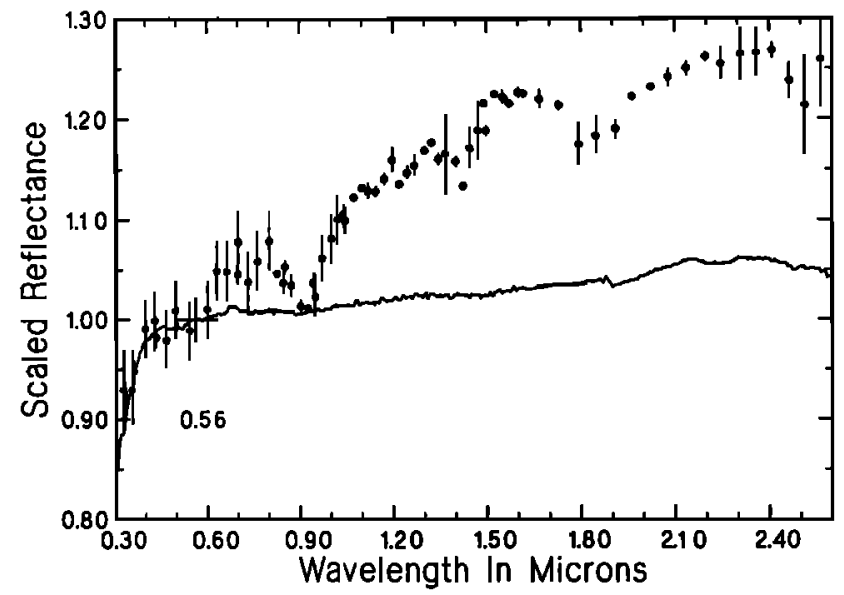

Fig. 12. Normalized reflectance spectra (scaled to 1 at $0.56 \mu \mathrm{m}$ ) of the 45- to $90-\mu \mathrm{m}$-sized acid-insoluble fraction of the Happy Canyon enstatite chondrite (line) and asteroid (44) Nysa [Gaffey et al., 1988]. plagioclase [Cloutis, 1985; Adams and Goullaud, 1978]. Again using plagioclase as a spectral analogy for enstatite, $5-10 \mathrm{wt} \%$ of an iron bearing pyroxene added to the iron-free material either intimately or areally would be sufficient to produce two absorption bands comparable to those seen in the spectrum of Nysa, in terms of wavelength position and intensity. This abundance would also not excessively reduce the absolute albedo. The lowest petrologic grade enstatite chondrites (E3) contain sufficient amounts of higher iron pyroxene to produce such absorption bands [Lusby et al., 1987], but these bands are not apparent in E3 reflectance spectra [Miyamoto, 1987] perhaps because of the presence of accessory opaque components.

The absorption bands present in Nysa's spectrum near 1.4 $\mu \mathrm{m}$ and $1.9 \mu \mathrm{m}$ are commonly associated with some form of water, either molecular or structural. If these bands are real and not due to atmospheric absorption, they suggest that a hydrated silicate is probably present on the surface of Nysa. Because of the high transparency of enstatite, a small amount of a spectrally featured material mixed in with, or adjacent to, enstatite will be detectable. Readily apparent compositional variations in meteorites over various scales are not unknown [Nininger, 1979]. More significantly, distinct light and dark lithologies are present in the Cumberland Falls and Allan Hills 78113 aubrites [Lovering, 1962; Binns, 1969; Neal and Lipschutz, 1981; Verkouteren and Lipschutz, 1983; Lipschutz et al., 1988]. The dark portions of these meteorites contain abundant low-iron pyroxene which could account for the absorption bands present in the Nysa spectrum at $0.9 \mu \mathrm{m}$ and $1.8 \mu \mathrm{m}$. The dark xenoliths are a low petrologic grade chondritic material, and at least some are highly shocked [Binns, 1969; Verkouteren and Lipschutz, 1983; Lipschutz et al., 1988]. Reflectance spectra are not available for these xenoliths, but other highly shocked chondrites show many desirable spectral features including a red slope similar to Nysa, weak mafic silicate absorption bands and a weak absorption band near $1.4 \mu \mathrm{m}$ [Gaffey, 1976]. However, the latter may be due to terrestrial weathering. Low petrologic grade meteorites that are mineralogically similar to the aubrite xenoliths, such as Renazzo and ALH85085, contain abundant hydrated silicates [Mason and Witk, 1962; Van Schmus and Hayes, 1974; Welsberg et al., 1988]. While hydrated silicates have not been documented for the aubrite xenoliths, the xenoliths potentially may possess all the spectral characteristics necessary to account for all of the absorption features seen in the reflectance spectrum of Nysa.

The polarimetric data for Nysa can be matched by either aubrites or enstatite chondrites. Consequently, a small amount of a dark component added to an aubrite would not drastically affect the match between Nysa and the aubrites. The polarimetric data for Nysa also suggest a largely fine-grained surface, in agreement with the spectral interpretation [Dollfus et al., 1971; Zellner, 1975; Zellner et al., 1977a; Dollfus et al., 1979].

The observational data for Nysa are all consistent with an aubrite-like surface assemblage with $<10 \%$ areally distributed or intimately mixed material similar to the Cumberland Falls chondritic inclusions. A significant portion of the surface is composed of fine-grained ( $<45 \mu \mathrm{m}$ size) materials.

\section{Summary}

The spectral detectability of mafic silicates associated with metal, carbon, and magnetite is strongly dependent on the particle sizes of the phases, their chemistries, crystal structures, 
and abundances. The reflectance spectrum of iron meteorite metal essentially consists of two linear segments with red slopes (increasing reflectance toward longer wavelengths) and an inflection point near $1 \mu \mathrm{m}$. The $1.8 \mu \mathrm{m} / 0.7 \mu \mathrm{m}$ reflectance ratio can be used to highlight differences due to grain size and chemical variations. The smallest grain size of meteoritic metal measured $(<45 \mu \mathrm{m})$ has a $1.8 \mu \mathrm{m} / 0.7 \mu \mathrm{m}$ reflectance ratio of 1.55 , with the ratio increasing with increasing grain size. There appears to be no simple correlation between nickel content and spectral slope in the nonmeteoritic metals. The detection limit for mafic silicates in metal-silicate mixtures is strongly dependent on grain size and the type of silicate. For olivine +metal mixtures the lower limit for detection is $-20 \mathrm{wt} \%$ olivine. Orthopyroxene has a lower detection limit of $-10 \mathrm{wt} \%$.

The acid-insoluble fraction of an E7 chondrite is predominantly enstatite, has a flat reflectance spectrum at $>0.4 \mu \mathrm{m}$ with high overall reflectance, and a $1.8 \mu \mathrm{m} / 0.7 \mu \mathrm{m}$ reflectance ratio of -1 . This material is a good spectral analogue to the aubrites.

Fine-grained carbon is very effective at suppressing mafic silicate absorption bands. Fine-grained olivine $(<45 \mu \mathrm{m})$ is almost completely obscured by 0.5 wt \% carbon, while a coarser fraction $(45-90 \mu \mathrm{m})$ retains a well-defined $\mathrm{Fe}^{2+}$ absorption band when mixed with the same amount of carbon. If the olivine has a mean grain size in the tens of microns, the olivine absorption band will be resolvable for carbon abundances present in all known meteorite types. Pyroxene-carbon mixtures have similar detection limits.

Magnetite is not very effective at suppressing olivine absorption features. A $50 / 50$ mixture of olivine/magnetite shows absorption features due to ferrous iron. Finer-grained magnetite imparts a bluer slope to reflectance spectra. A combination of carbon and magnetite would probably be required to mimic the reflectance spectra of olivine-bearing carbonaceous chondrites with flat or blue slopes.

The reflectance spectrum of the $M$-class asteroid Psyche is not directly comparable to those of iron meteorite powders. However, the overall shape of the spectrum more closely resembles that of iron meteorites than enstatite chondrites, and lies on a trend suggesting an appreciable fine-grained $(<45$ $\mu \mathrm{m}$ size) component. This interpretation is also consistent with the constraints imposed by radar and polarimetric observations.

The reflectance spectrum of the best-characterized E-class asteroid, 44 Nysa, is interpreted to indicate an aubrite like surface for this asteroid. The slight red slope and weak absorption bands present in the asteroid spectrum can probably be accounted for by a minor $(<10 \%)$ additional component similar to the dark inclusions found in the Cumberland Falls aubrite. The reflectance spectra also suggest that a significant portion of the surface materials on Nysa are fine grained $(<45$ $\mu \mathrm{m}$ size).

The $\mathrm{M}$ - and $\mathrm{E}$-class asteroids are concentrated in the inner part of the main asteroid belt [Gradie and Tedesco, 1982]. If the interpretations of the surface assemblages for representative members of these groups can be extended to all the members of the group, then the case for pervasive and widespread early heating of inner part of the main asteroid belt is strengthened [Bell, 1986].

Acknowledgments. This study was supported by grants-in-aid of research from the Central Research Fund of the University of Alberta (to D.G.W.S.), from Sigma Xi, The Scientific Research Society and the Geological Society of America 3741-87 (to E.A.C.) and NASA Planetary Geology and
Geophysics grant NAGW 642 (to M.J.G.). Electron microprobe analysis of the minerals was made possible through the assistance of E.D. Ghent and John Machacek at the University of Calgary. Thanks to Roger Clark and Greg Swayze of the U.S. Geological Survey and Carle Pieters and Stephen Pratt at Brown University for providing access to the spectrometer facility and NASA RELAB spectrometer at the respective institutions. Special thanks to Ron Eyton, Douglas Hube, Lucy McFadden, and Jeffrey Bell for helpful reviews of this manuscript, and to Jeffrey Bell for permission to include the most recent asteroid spectral data.

\section{REFERENCES}

Adams, J.B., Interpretation of visible and near-inf rared diff use reflectance spectra of pyroxenes and other rock-forming minerals, in Infrared and Raman Spectroscopy of Lunar and Terrestrial Minerals, edited by C. Karr Jr., pp. 91-116, Academic, San Diego, Calif., 1975.

Adams, J.B., and L.H. Goullaud, Plagioclase feldspars: Visible and near infrared diffuse reflectance spectra as applied to remote sensing, Proc. Lunar Planet. Scl. Conf., 9th, 2901-2909, 1978.

Auten, T.A., On the brittleness of Gibeon meteoritic iron, Meteoritics, 8, 189-196, 1973.

Baldanza, B., and G. Pralla, Dynamically deformed structures in some meteorites, in Meteorite Research, edited by P.M. Millman, pp. 806-825, D. Reidel, Hingham, Mass., 1969.

Bauman, A.J., J.R. Devaney, and E.M. Bollin, Allende meteorite carbonaceous phase: Intractable nature and scanning electron morphology, Nature, 241, 264-267, 1973.

Bell, J.F., Mineralogical evolution of meteorite parent bodies (abstract), Lunar Planet. Scl. Conf., XVII, 985-986, 1986.

Bell, J.F., M.J. Gaffey, and B.R. Hawke, Spectroscopic identification of probable pallasite parent bodies (abstract), Meteoritics, 19, 187-188, 1984.

Bell, J.F., P.D. Owensby, B.R. Hawke, and M.J. Gaffey, The 52-color asteroid survey: Final results and interpretation (abstract), Lunar Planet. Sci. Conf., XIX, 57-58, 1988.

Bell, P.M., and H.K. Mao, Optical spectra of thin metallic coatings with applications to the spectra of lunar soil samples (abstract), Lunar Sci. Conf., VIII, 88-90, 1977.

Binns, R.A., A chondritic inclusion of unique type in the Cumberland Falls meteorite, in Meteorite Research, edited by P.M. Millman, pp. 696-704, D. Reidel, Hingham, Mass., 1969.

Blake, D. F., F. Freund, K.F.M. Krishnan, C.J. Echer, R. Shipp, T.E. Bunch, A.G. Tielens, R.J. Lipar1, C.J.D. Hetherington, and S. Chang, The nature and origin of interstellar diamond, Nature, 332, 611-613, 1988.

Blodgett Jr., A.J., and W.E. Spicer, Experimental determination of the optical density of states in iron, Phys. Rey., 158, 514-523, 1967.

Britt, D.T., and C.M. Pieters, Bidirectional reflectance properties of iron-nickel meteorites, Proc. Lunar Planet. Sct. Conf., 18th, 503-512, 1988.

Buchwald, V.F., Handbook of Iron Meteorites, University of California Press, Berkeley, 1975.

Buseck, P.R., Pallasite meteorites-Mineralogy, petrology, and geochemistry, Geochim. Cosmochim. Acta, 41, 711-740, 1977.

Chapman, C.R., Asteroids as meteorite parent bodies: The astronomical perspective, Geochim. Cosmochim. Acta, 40, $701-719,1976$. 
Chapman, C.R., The asteroids: Nature, interrelations, origin, and evolution, in Asterolds, edited by T. Gehrels, pp. 25-60, University of Arizona Press, Tucson, 1979.

Chapman, C.R., and M.J. Garfey, Reflectance spectra for 277 asteroids, in Asterolds, edited by T. Gehrels, pp. 655-687, University of Arizona Press, Tucson, 1979.

Chapman, C.R., and J.W. Salisbury, Comparisons of meteorite and asteroid spectral reflectivities, Icarus, 19, 507-522, 1973.

Clark, R.N., A large-scale interactive one dimensional array processing system, Publ. Astron. Soc. Pac., 92, 221-224, 1980.

Clark, R.N., Spectral properties of mixtures of montmorillonite and dark carbon grains: Implications for remote sensing minerals containing chemically and physically adsorbed water, J. Geophys. Res., 88, 10,635-10,644, 1983.

Clark, R.N., and T.L. Roush, Reflectance spectroscopy: Quantitative analysis techniques for remote sensing applications, J. Geophys. Res., 89, 6329-6340, 1984.

Cloutis, E.A., Interpretive techniques for reflectance spectra of mafic silicates, M.Sc. thesis, Univ. of Hawaii, Honolulu, 1985.

Comerford, M.F., Phosphide and carbide inclusions in iron meteorites, in Meteorite Research, edited by P.M. Millman, pp. 780-794, D. Re1del, Hingham, Mass., 1969.

Crown, D.A., and C.M. Pieters, Spectral properties of plagioclase and pyroxene mixtures and the interpretation of lunar soil spectra, Icarus, 72, 492-506, 1987.

Cruikshank, D.P., and W.K. Hartmann, The meteorite-asteroid connection: Two olivine-rich asteroids, Science, 223, 281-283, 1984.

Deines, P., and F.E. Wickman, The stable carbon isotopes in enstatite chondrites and Cumberland Falls, Geochim. Cosmochim. Acta, 49, 89-95, 1985.

Doan Jr., A.S., and J.I. Goldstein, The formation of phosphides in iron meteorites, in Meteorite Research, edited by P.M. Millman, pp. 763-779, D. Reidel, Hingham, Mass., 1969.

Dollfus, A., E. Bowell, and C. Titulaer, Polarimetric properties of the lunar surface and its interpretation, Part II, Terrestrial samples in orange light, Astron. Astrophys., 10, 450-466, 1971.

Dollfus, A., J.-C. Mandeville, and M. Duseaux, The nature of the M-type asteroids from optical polarimetry, Icarus, 37, 124-132, 1979.

Dollfus, A., A. Cailleux, B. Cervelle, C.T. Hua, and J.-C. Mandeville, Reflectance spectrophotometry extended to u.v. for terrestrial, lunar and meteoritic samples, Geochim. Cosmochim. Acta, 44, 1293-1310, 1980.

Easton, A.J., Grain-size distribution and morphology of metal in E-chondrites, Meteoritics, 18, 19-27, 1983.

Eaton, N., S.F. Green, R.S. McCheyne, A.J. Meadows, and G.J. Veeder, Observations of asteroids in the 3- to $4-\mu \mathrm{m}$ region, Icarus, 55, 245-249, 1983.

Egan, W.G., and T. Hilgeman, The rings of Saturn: A frost-coated semiconductor?, Icares, 30, 413-421, 1977.

Feierberg, M.A., H.P. Larson, and C.R. Chapman, Spectroscopic evidence for undifferentiated S-type asteroids, Astrophys. J., 257, 361-372, 1982.

Gaffey, M.J., A systematic study of the spectral reflectivity characteristics of the meteorite classes with applications to the interpretation of asteroid spectra for mineralogical and petrological information, $\mathrm{Ph} . \mathrm{D}$. dissertation, Mass. Inst. of Technol., Cambridge, 1974.

Gaffey, M.J., Spectral reflectance characteristics of the meteorite classes, J. Geophys. Res., 81, 905-920, 1976.
Gaffey, M.J., Optical and spectral properties of the low albedo meteorites: Applications to the interpretation of the spectra of dark asteroids (abstract), Lunar Planet. Scl. Conf., IX, 362-364, 1978.

Gaffey, M.J., Mineralogically diagnostic features in the visible and near-infrared reflectance spectra of carbonaceous chondrite assemblages (abstract), Lunar Planet. Scl. Conf., $X I, 312-313,1980$.

Gaffey, M.J., Rotational spectral variations of asteroid (8) Flora: Implications for the nature of the $S$-type asteroids and for the parent bodies of the ordinary chondrites, Icarus, 60 , 83-114, 1984.

Gaffey, M.J., The spectral and physical properties of metal in meteorite assemblages: Implications for asteroid surface materials, Icarus, 66, 468-486, 1986.

Gaffey, M.J., Thermal history of the asteroid belt: Implications for accretion of the terrestrial planets (abstract), Lunar Planet. Sci. Conf., XIX, 369-370, 1988.

Gaffey, M.J., and T.B. McCord, Asteroid surface materials: Mineralogical characterizations from reflectance spectra, Space Sct. Rev., 21, 555-628, 1978.

Gaffey, M.J., J.F. Bell, and D.P. Cruikshank, Reflectance spectroscopy and asteroid surface mineralogy, paper presented at Asteroids II, Planetary Science Institute, Tucson, Ariz., March 8, 1988.

Gibson Jr., E.K., Nature of the carbon and sulphur phases and inorganic gases in the Kenna ureilite, Geochim. Cosmochim. Acta, 40, 1459-1464, 1976.

Gibson, E.K., C.B. Moore, and C.F. Lewis, Total nitrogen and carbon abundances in carbonaceous chondrites, Geochim. Cosmochim. Acta, 35, 599-604, 1971.

Gorban, N.Y., and V.S. Stashchuk, Optical absorption of $\mathrm{Ni}-\mathrm{Fe}$ alloys, Opt. Spectrosc., 37, 202-203, 1974.

Gorban, N.Y., V.S. Stashchuk, A.V. Shirin, and A.A. Shishlovskii, Optical properties of nickel-iron alloys in the region of interband transitions, Opt. Spectrosc., 35, 295-298, 1973.

Gradie, J., and E. Tedesco, Compositional structure of the asteroid belt, Sclence, 216, 1405-1407, 1982.

Gradie, J., and J. Veverka, The composition of the Trojan asteroids, Nature, 283, 840-842, 1980.

Grady, M.M., I.P. Wright, L.P. Carr, and C.T. Pillinger, Compositional differences in enstatite chondrites based on carbon and nitrogen stable isotope measurements, Geochim. Cosmochlm. Acta, 50, 2799-2813, 1986.

Grossman, J.N., A.E. Rubin, and G.J. MacPherson, Allan Hills 85085: An out-of-the-ordinary enstatite-rich carbonaceous chondrite (abstract), Lunar Planet. Sct. Conf., XIX, 433-434, 1988.

Hapke, B., Bidirectional reflectance spectroscopy, 1, Theory, $J$. Geophys. Res., 86, 3039-3054, 1981.

Hunt, G.R., J.W. Salisbury, and C.J. Lenhoff, Visible and near-inf rared spectra of minerals and rocks, III, Oxides and hydroxides, Mod. Geol., 2, 195-205, $1971 a$.

Hunt, G.R., J.W. Salisbury, and C.J. Lenhoff, Visible and near-infrared spectra of minerals and rocks, IV, Sulphides and sulphates, Mod. Geol., 3, 1-14, $1971 b$.

Johnson, T.V., and F.P. Fanale, Optical properties of carbonaceous chondrites and their relationship to asteroids, $J$. Geophys. Res., 78, 8507-8518, 1973.

Keil, K., Mineralogical and chemical relationships among enstatite chondrites, J. Geophys. Res., 73, 6945-6976, 1968.

Kerridge, J.F., Some observations on the nature of magnetite in the Orgueil meteorite, Earth Planet. Scl. Lett., 9, 299-306, 1970. 
King, T.V.V., and W.I. Ridley, Relation of the spectroscopic reflectance of olivine to mineral chemistry and some remote sensing implications, J. Geophys. Res., 92, 11,457-11,469, 1987.

Larson, H.P., and G.J. Veeder, Infrared spectral reflectances of asteroid surfaces, in Asteroids, edited by T. Gehrels, pp. 724-744, University of Arizona Press, Tucson, 1979.

Lipschutz, M.E., R.M. Verkouteren, D.G.W. Sears, F.A. Hasan, M. Prinz, W.K. Weisberg, C.E. Nehru, J.S. Delaney, L. Grossman, and M. Boily, Cumberland Falls chondritic inclusions: III. Consortium study of relationship to inclusions in Allan Hills 78113 aubrite, Geochtm. Cosmochim. Acta, 52, 1835-1848, 1988.

Lovering, J.F., The evolution of the meteorites-Evidence for the co-existence of chondritic, achondritic and iron meteorites in a typical parent meteorite body, in Researches on Meteorites, edited by C.B. Moore, pp. 179-197, John Wiley, New York, 1962.

Lusby, D., E.R.D. Scott, and K. Keil, Ubiquitous high-FeO silicates in enstatite chondrites, Proc. Lunar Planet. Sct. Conf., 17th, Part 2, J. Geophys. Res., 91, suppl., E679-E695, 1987.

Marcus, H.L., and L.H. Hackett Jr., The low temperature fracture behavior of iron-nickel meteorites, Meteorltlcs, 9, 371-376, 1974.

Mason, B., Meteoriles, John Wiley, New York, 1962.

Mason, B., The enstatite chondrites, Geochim. Cosmochim. Acta, 30, 23-39, 1966.

Mason, B., and H.B. Wiik, The Renazzo meteorite, Am. Mus. Novit., 2106, 1-11, 1962.

Matsui, T., and P.M. Schultz, On the brittle-ductile behavior of iron meteorites: New experimental constraints, Proc. Lunar Planet. Scl. Conf., 15th, Part 1, J. Geophys. Res., 89, suppl., C323-C328, 1984.

McCord, T.B., J.B. Adams, and T.V. Johnson, Asteroid Vesta: Spectral reflectivity and compositional implications, Science, 168, 1445-1447, 1970.

McFadden, L.A., Spectral reflectance of near-Earth asteroids: Implications for composition, origin and evolution, Ph.D. dissertation, Univ. of Hawaii, Honolulu, 1983.

Miyamoto, M., Diffuse reflectance from $0.25 \mu \mathrm{m}$ to $25 \mu \mathrm{m}$ of the Yamato-691 enstatite chondrite, Proceedings of Eleventh Symposium on Antarctic Meteorites, Mem. Nall. Inst. Polar Res. Spec. Issue Jpn., 46, 123-J30, 1987.

Miyamoto, M., A. Mito, Y. Takano, and N. Fujii, Spectral reflectance $(0.25-2.5 \mu \mathrm{m})$ of powdered olivines and their bearing on surface materials of asteroids, Proceedings of Sixth Symposium on Antarctic Meteorites, Mem. Natl. Inst. Polar Res. Spec. Issue Jpn., 20, 345-361, 1981.

Miyamoto, M., A. Mito, and Y. Takano, An attempt to reduce the effects of black material from the spectral reflectance of meteorites or asteroids, Proceedings of Seventh Symposium on Antarctic Meteorites, Mem. Nall. Inst. Polar Res. Spec. Issue Jpn., 25, 291-307, 1982.

Moore, C.B., and C. Lewis, Carbon abundances in chondritic meteorites, Science, 149, 317-318, 1965.

Morris, R.V., H.V. Lauer Jr., C.A. Lawson, E.K. Gibson Jr., G.A. Nace, and C. Stewart, Spectral and other physicochemical properties of submicron powders of hematite $\left(\alpha-\mathrm{Fe}_{2} \mathrm{O}_{3}\right)$, maghemite $\left(\gamma-\mathrm{Fe}_{2} \mathrm{O}_{3}\right)$, magnetite $\left(\mathrm{Fe}_{3} \mathrm{O}_{4}\right)$, goethite $(\alpha-\mathrm{FeOOH})$, and lepidocrocite $(\gamma-\mathrm{FeOOH}), J$ Geophys. Res., 90, 3126-3144, 1985.

Nagy, B., Carbonaceous Meteorites, Elsevier, Amsterdam, 1975.
Neal, C.W., and M.E. Lipschutz, Cumberland Falls chondritic inclusions: Mineralogy/petrology of a forsterite chondrite suite, Geochim. Cosmochtm. Acta. 45, 2091-2107, 1981.

Nininger, H.H., The Bondoc meteorite: A one-ton sample of an asteroid? (abstract), Meteoritics, 14, 498-499, 1979.

Olsen, E.J., T.E. Bunch, E. Jarosewich, A.F. Noonan, and G.I. Huss, Happy Canyon: A new type of enstatite achondrite, Meteoritics, 12, 109-123, 1977.

Ostro, S.J., D.B. Campbell, and I.I. Shapiro, Mainbelt asteroids: Dual-polarization radar observations, Science, 229, 442-446, 1985.

Pieters, C.M., Strength of mineral absorption features in the transmitted component of near-infrared light: First results from RELAB, J. Geophys. Res., 88, 9534-9544, 1983.

Remo, J.L., and A.A. Johnson, A preliminary study of the ductile-brittle transition under impact conditions in material from an octahedrite, J. Geophys. Res., 80, 3744-3748, 1975.

Salisbury, J.W., and Hunt, G.R., Meteorite spectra and weathering, Jour. Geophys. Res., 79, 4439-4441, 1974.

Salisbury, J.W., G.R. Hunt, and C.J. Lenhoff, Visible and near-infrared spectra: X. Stony meteorites, Mod. Geol., 5, $115-126,1975$.

Singer, R.B., Near-infrared spectral reflectance of mineral mixtures: Systematic combinations of pyroxenes, olivine, and iron oxides, J. Geophys. Res., 86, 7967-7982, 1981.

Van Der Stap, C.C.A.H., D. Heymann, R.D. Vis, and H. Verheul, Mapping of carbon concentrations in the Allende meteorite with the ${ }^{12} \mathrm{C}(\mathrm{d}, \mathrm{p})^{13} \mathrm{C}$ method, Proc. Lunar Planet. Sci. Conf. 16th, Part 2, J. Geophys. Res., 91, suppl., D373-D377, 1986.

Van Schmus, W.R., and J.M. Hayes, Chemical and petrographic correlations among carbonaceous chondrites, Geochim. Cosmochim. Acta, 38, 47-64, 1974.

Vdovykın, G.P., Ureilites, Space Scl. Rev., 10, 483-510, 1970.

Veeder, G.J., D.L. Matson, and J.C. Smith, Visual and inf rared photometry of asterolds, Astron. J., 83,651-663,1978.

Verkouteren, R.M., and M.E. Lipschutz, Cumbeiland Falls chondritic inclusions, II, Trace element contents of forsterite chondrites and meteorites of similar redox state, Geochim. Cosmochim. Acta, 47, 1625-1633, 1983.

Vilas, F., and M.J. Gaffey, Weak $\mathrm{Fe}^{2+}-\mathrm{Fe}^{3+}$ charge transfer absorption features seen in CM2 carbonaceous chondrites and narrowband reflectance spectra of primitive asteroids (abstract), Lunar Planet. Scl. Conf., XX, 1156-1157, 1989.

Wagner, J.K., B.W. Hapke, and E.N. Wells, Atlas of reflectance spectra of terrestrial, lunar, and meteoritic powders and frosts from 92 to $1800 \mathrm{~nm}$, Icarus, 69, 14-28, 1987.

Watson, F.G., Reflectivity and color of meteorites, Proc. Natl. Acad. Sci. U.S.A., 24, 532-537, 1938.

Watters, T.R., and M. Prinz, Aubrites: Their origin and relationship to enstatite chondrites, Proc. Lunar Planet. Scl. Conf., 10th, 1073-1093, 1979.

Watters, T.R., M. Prınz, E.R. Rambaldi, and J.T. Wasson, ALHA78113, Mt. Egerton and the aubrite parent body, Meteoritics, 15, 386, 1980.

Weidner, V.R., and J.J. Hsia, Reflection properties of pressed polytetrafluoroethylene powder, J. Opt. Soc. Am., 71, 856-861, 1981.

Weisberg, M.K., M. Prinz, and C.E. Nehru, Petrology of ALH85085: A chondrite with unique characteristics, Earth Planet. Sci. Lett., 91, 19-32, 1988. 
Yolken, H.T., and J. Kruger, Optical constants of iron in the visible region, J. Opt. Soc. Am., 55, 842-844, 1965.

Zellner, B., 44 Nysa: An iron-depleted asteroid, Astrophys. J., 198, L45-L47, 1975.

Zellner, B., M. Leake, D. Mortison, and J.G. Williams, The E asteroids and the origin of the enstatite chondrites, Geochim. Cosmochim. Acta, 41, 1759-1767, 1977a.

Zellner, B., M. Leake, T. Lebertre, M. Duseaux, and A. Dollfus, The asteroid albedo scale: I. Laboratory polar:metry of meteorites, Proc. Lunar Sci. Conf., 8th, 1091-1110, $1977 b$.
E.A. Cloutis, R. St J. Lambert, and D.G.W. Smith, Department of Geology, University of Alberta, Edmonton, Alberta, Canada T6G 2E3.

M.J. Gaffey, Department of Geology, West Hall, Rensselaer Polytechnic Institute, Troy, NY 12181.

(Received March 31, 1989; revised July 25,1989 ; accepted August 4, 1989.) 